\title{
Caring for the Palliative Care amidst COVID-19 Pandemic
}

\author{
Mamak Tahmasebi ${ }^{1}$, Behdad Gharib ${ }^{2}$, Meisam Sharifzadeh ${ }^{2}$
}

${ }^{1}$ Gynecologist/Palliative Medicine Fellow, Cancer Institute, Tehran University of Medical Sciences, Tehran, Iran. ${ }^{2}$ Children's Medical Center, Tehran University of Medical Sciences, Iran.

\begin{abstract}
With or without COVID-19, "palliative care" is about basics. 1) Good control of symptoms due either to the disease or treatment, 2) Good decisions, especially when it becomes clear that control of the disease is no longer possible, with trying to help the patient do what means most to them, 3) Patient/family support in every phase of the illness from diagnosis throughout all phases of care until the moment of death, and 4) Care of bereaved person. Palliative care, the care of patients (adults or children) with probably fatal illnesses, whether they are still having anti disease therapy or not must occur in many places, many wards, clinics, at home, and even virtual. The COVID-19 crisis has a serious impact on patients' care, but with respect for every person, and a great deal of education, training and support of staff, we would overcome it successfully.
\end{abstract}

Keywords: Palliative care- COVID-19- Cancer care

Asian Pac J Cancer Care, 5 (Suppl 1), 243-245

The necessity of good care

In a period of two weeks between $20^{\text {th }}$ of April to $4^{\text {th }}$ of May, the number of new referrals to palliative medicine clinic reduced approximately $50 \%$ as against the same period of time in the last 4 years.

Providing health care has been seriously affected by the COVID-19 pandemic. Preventive measures such as social distancing and wearing mask negatively affected all aspects of patient-physician interaction. What could be more frightening than cancer? Fear of COVID-19 forced cancer patients to stay home, at the cost of needless suffering [1-2]. As each patient has limited stock of opioid medication, and based on my personal experience in palliative medicine clinic, caregivers even prefer to comfort their patients with street opium rather than bringing them to the hospital for instance for oxycodone prescription. "Staying home or going to the hospital?" is a new dilemma for patients, especially those with advanced cancer.

There are patients with advanced cancer who are aware of being in the last phase of their lives. For a large number of these terminally ill patients only a few weeks of survival are envisioned. While patients may have come into terms with their imminent mortality, enduring the physical suffering should not be allowed. Suffering is subjective
Submission Date: 06/03/2020Ａcceptance Date: 08/21/2020

and different from distress. Suffering is best understood as "a sense of impending personal disintegration" or as we might say "a sense of being about to go to pieces" [3] which may not be evident to the carer. No person should die with a sense of personal disintegration. Most people who are almost certain to die within a short period of time will require comfort and dignity in a highly personalized context.

A person with cancer and other comorbidities who decides to stay at home and not to be brought to the hospital, needs to understand that this decision may reduce the chance of his/her survival and increase the risk of his/her suffering. It is clear every person at home or in hospital needs good care, which consists of a) relief of the most distressing symptoms by application of what is known to be good clinical practice, b) emotional support for the person and his/her carers/family, and c) careful planning of care, so that all concerned parties know what to do and what to expect, and how to call for extra help. Palliative care is not exempt from this framework and should not be considered an alternative to good treatment or good ordinary home care.

The four principles of health care ethics include autonomy, beneficence, non-maleficence, and justice [4].

Corresponding Author:

Dr. Mamak Tahmasebi

Gynecologist/Palliative Medicine Fellow, Cancer Institute, Tehran University of Medical Sciences, Tehran, Iran.

Email:mamaktahma@yahoo.com 
"Autonomy" is described as the right of patient to have control over his or her body. However, making decision to stay home with the knowledge (for patient and family) that this might reduce the chances of survival, should NOT be seen as a decision to be allowed to die, even though that may be the most likely outcome. Additionally, beneficence obligates health care providers to use all they have in their power in the benefit of their patients, regardless of the situation. To ascertain "beneficence during pandemics" staying home decision will only be possible under the shadow of structured community care services and eClinics.

This premise is a shortcut in countries where disproportional investment on tertiary or specialized consultative health care services, lack of resources and knowledge in basic palliative care, and lack of governmental advocacy for home-based palliative care further damaged the foundation of community care services [5].

\section{A high-tech solution for medicine during pandemic}

Telehealth, as an alternative option for providing health care during COVID-19 outbreak, initially conceived as a reasonable solution. Technology can be applied to address many challenges faced by health care system. In spite of numerous attempts to define telehealth, the question of whether digital visits can make up for the "good" care remained unanswered.

The telephone, electronic mails, and smart phones are alternative modes of communication and each has its own advantages and limitations. We need a new definition for "communication" in medicine when it is hard to maintain the personal connection that is a crucial part of palliative care. Here is an example of the challenges that physicians have to face during outbreak:

Ms. S. is a 79-year-old fragile woman with metastatic breast cancer to the lungs. Two weeks ago, she was referred to the emergency department (ED) for dyspnea and her chest $\mathrm{x}$-ray revealed severe pleural effusion in the right lung. The next day, she was discharged home after paracentesis and relatively good control of her symptoms. One week after at 8:00 pm, her daughter called her physician and complained about her mother's low-grade fever and dyspnea. Now the physician is forced to add COVID-19 to the familiar list of differential diagnosis of dyspnea. What would be the best decision for her? Does she know about her prognosis? Have the goals of care been ever discussed with the patient?

There are textbooks about the benefits of high-tech communication like smartphones for health care system. This leaves no room for doubt concerning the significance of digital technology in the future of medical science. Nonetheless, health care providers need to be confident about quality of care. Aside from all technical challenges in using telemedicine such as ease of use (especially for elderly), accessibility of appropriate infrastructure, and broadband connectivity [6], as highlighted in the case above, physical examination that it is a crucial foundation of medical diagnosis is abrogated during a virtual visit. It is extremely important for the physician to decide when a physical examination is critical and obviously, it would not be easy decision.

Our knowledge about the accuracy of virtual conveyance of emotions is still very limited. How effective would be the communication between the physician and a dying patient if physician were unable to hold patient's hand or offering napkins or a glass of water to relatives. The same concerns will be raised if the physician has to talk about the advance directive, goals of care, clinical decision making, and even palliative sedation.

\section{Palliative Care for children}

While children seem to be less affected by COVID-19 than adults, and most infected children have no or mild symptoms, those with underlying health conditions expected to have more severe presentations [7-8]. The families of the children with chronic and/or life-threatening illnesses are mainly relying on the governmental health services. Similar to adults, the increasing fear and the stress of contracting COVID-19 may lead the families to stop visiting the hospitals or even health care providers at home [9]. Addressing the emotional problems of the children and the parents such as fear, anxiety and isolation in the time of global fear and anxiety is an important task that can be an easily forgotten.

The health care team, who has been taking care of children with life-threatening illnesses, encounter with challenges that they may have never experienced before. A 12-year-old girl, with refractory leukemia and COVID-19- induced respiratory distress or a 13-year-old boy with several relapses of leukemia and severe COVID-19 induced acute respiratory distress syndrome, were just some challenging examples. We had to deal with during pandemic. Their parents refrained to come to the hospital because of the recommended social distancing, while the facilities for telemedicine were not available for them. The health care team tried to convince them to follow the care in the hospital and provide the necessary medical and palliative care for them. The hospital team were challenging with the COVID patients and they were also worrying for health of their own family, the community were panicked and in the middle of the chaos and rush, the importance of the proven and necessary pain remedies and addressing the emotional needs of the patients and their families were near to be ignored. Unfortunately, we lost both patients and the remaining dilemma that left the health team in agony whether they could take an alternative approach which would have reduced the sufferings of the patients.

\section{The last word}

According to the World Health Organization (WHO), palliative care is: "An approach that improves the quality of life of patients and their families facing the problem associated with life-threatening illness, through the prevention and relief of suffering by means of early identification, impeccable assessment, treatment of pain and other problems, physical, psychosocial and spiritual' [10]. Palliative care should not be regarded as a luxury 
but a necessity and, the holistic approach of palliative care means that it is the business of all health care system.

An essential aspect of palliative care is to conserve the dignity of the patient. As long as patient's value and worth are acknowledged, she/he is cared for with respect and empathy, her/his voice is heard regarding the process of dying, and her/his physical and emotional suffering are minimized [11-12]. This is on physicians and policy makers to modify and readjust the current standards of care according to the emerging pandemic.

In conclusion, the COVID-19 crisis influences the care of our patients very seriously, not only because some stay away from hospital and risk denying themselves good comfort care, but also, we clinicians experience the limitations of online care.

\section{References}

1. Richards M, Anderson M, Carter P, Ebert B, Mossialos E. The impact of the COVID-19 pandemic on cancer care. Nature Cancer. 2020 May 20;:1-3.

2. Rao K, Singhai P, Rao S, Salins N. Palliative care for advanced cancer patients in the COVID-19 pandemic: Challenges and adaptations. Cancer Research, Statistics, and Treatment. 2020;3(5):127. https://doi.org/10.4103/crst.crst_130_20

3. Cassel EJ. The Nature of Suffering and the Goals of Medicine. New England Journal of Medicine. 198203 18;306(11):639645. https://doi.org/10.1056/nejm198203183061104

4. Furlong E, editor. Health Care Ethics. Jones \& Bartlett Learning. 2018 Jan 16.

5. Carey ML, Zucca AC, Freund MA, Bryant J, Herrmann A, Roberts BJ. Systematic review of barriers and enablers to the delivery of palliative care by primary care practitioners. Palliative Medicine. 2019 09 05;33(9):1131-1145. https:// doi.org/10.1177/0269216319865414

6. Finn N, Bria W. Digital communication in medical practice. Springer Science \& Business Media. 2009 Apr 9;

7. Dong Y, Mo X, Hu Y, Qi X, Jiang F, Jiang Z, Tong S. Epidemiology of COVID-19 Among Children in China. Pediatrics. 202003 16;145(6):e20200702. https://doi. org/10.1542/peds.2020-0702

8. Bialek S, Gierke R, Hughes M, McNamara LA, Pilishvili T, Skoff T. Coronavirus Disease 2019 in Children - United States, February 12-April 2, 2020. MMWR. Morbidity and Mortality Weekly Report. 202004 10;69(14):422-426. https://doi.org/10.15585/mmwr.mm6914e4

9. http://globalpalliativecare.org/covid-19/uploads/briefingnotes/briefing-note-caring-for-children-with-underlyingserious-health-conditions-during-the-covid-19-pandemic. pdf.

10. World Health Organisation (2002) 'National cancer control programmes: policies and managerial guidelines', $2^{\text {nd }}$ edition, WHO, Geneva.

11. Kennedy G. The importance of patient dignity in care at the end of life. Ulster Med J. 2016;85(1):45-8.

12. Baillie L, Matiti M. Dignity, equality and diversity: an exploration of how discriminatory behaviour of healthcare workers affects patient dignity. Diversity in Health and Social Care. 2013;10(1):5-12.

\section{(c) (i) (8)}

This work is licensed under a Creative Commons AttributionNon Commercial 4.0 International License. 